\title{
ENCOUNTERS WITH UNJUST AUTHORITY
}

Bruce Fireman, William A. Gamson,

Steve Rytina, and Bruce Taylor

University of Michigan

January 1977

CRSO Working Paper 非67

Copies available through:

Center for Research on Social Organization University of Michigan

330 Packard Street

Ann Arbor, Michigan 48109 


\section{Encounters with Unjust Authority}

by Bruce Fireman, William A. Gamson.

Steve Rytina, and Bruçe Taylor*

Center For Research on Social Organization

University of Michigan

January, 1978

(Chapter to appear in Louis Kriesberg, ed., Research in Social Movements, Conflicts, and Change, Vol. II, JAI Press.)

*Authors listed alphabetically 


\section{Encounters with Unjust Authority}

Management speed-ups followed by spontaneous worker sitdowns

were becoming widespread in several industries by the mid-1930s. In one company, management suddenly cut the number of "bow-men" (those who welded the angle irons across car roofs) from four to three. ${ }^{1}$ The remaining three bow-men were non-union men, two brothers named Perkins and an Italian named Joe Urban. Confronting the fait accompli, they simply stopped working. "The foreman and superintendent rushed over and tried to talk them into going back to work, but the men just sat there arguing until 20 unfinished jobs had passed on the production line. The whole Department followed the argument with intense excitement" (Brecher, p. 234).

The three men finally agreed to resume work pending further discussion of the issue, but when they reported to work the next day, they were given firing slips. They showed these slips to a union activist in the shop named Bud Simons, who reacted by running "through the main welding and soldering department yelling, "The Perkins boys were fired! Nobody starts working!"

Kraus (1947) describes the ensuing events in useful detail:

The whistle blew. Every man in the Department stood at his station, a deep, significant tenseness in him. The foreman pushed the button and the skeleton bodies, already partly assembled when they got to this point, began to rumble forward. But no one lifted a hand. All eyes were turned to Simons who stood out in the aisle by himself.

The bosses ran about like mad.

"Whatsamatter? Whatsamatter? Get to work!" they shouted. 
But the men acted as though they never heard them. One or two of them couldn't stand the tension. Habit was deep in them, and it was like physical agony for them to see the bodies pass untouched. They grabbed their tools and chased after them. "Rat! Rat!" the men growled without moving and the others came to their senses.

The superintendent stopped by the "bow-men".

"You're to blame for this!" he snarled.

"So what if we are?" little Joe Urban, the Italian cried, overflowing with pride. "You ain't running your line, are you?"

That was altogether too much. The superintendent grabbed Joe and started for the office with him. The two went down the entire line, while the men stood rigid as though awaiting the word of command . . . Simons, a torch-solderer, was almost at the end of the line. He too was momentarily held in vise by the superintendent's overt act of authority. The latter had dragged Joe Urban past him when he finally found the presence of mind to call out:

"Hey, Teefee, where you going?"

It was spoken in just an ordinary conversational tone, and the other was taken so aback he answered the really impertinent question.

"I'm taking him to the office to have a little talk with him." Then suddenly he realized and got mad. "Say, I think I'11 take you along too!"

That was his mistake.

"No you wont!" Simons said calmly.

"Oh yes I will!" and he took hold of his shirt. 
Simons yanked himself loose.

And suddenly, at this simple act of insurgence, Teefee realized his danger. He seemed to become acutely conscious of the long silent men and felt the threat of their potential strength. They had been transformed into something he had never known before and over which he no longer had any command. He let loose of Simons and started off again with Joe Urban, hastening his pace. Simons yelled:

"Come on, fellows, don't let them fire little Joe!"

About a dozen boys shot out of line and started after Teefee. The superintendent dropped Joe like a hot poker and deer-footed it for the door.

This encounter led immediately to a negotiation between a shop committee led by Simons and the plant manager. The Committee insisted that the Perkins boys be rehired immediately and be brought back on the line before they would resume work. They won this demand, even though the Perkins boys had already left for home and took several hours to locate. Brecher (1972, p. 238) comments that "Largely in response to this victory, United Auto Workers' membership in Flint increased from 150 to 1,500 within two weeks."

In 1964, three decades 1ater, students at the University of California's Berkeley campus gathered for a rally in front of the campus administration building, Sproul Hall. It was an early stage in the emerging Berkeley Free Speech Movement. Eight students had been suspended on the previous day for deliberately violating a University ban against political activity on campus grounds. Heirich (1971) gives a detailed account of the encounter that day. 
About an hour and a half before the rally was scheduled to begin, a campus civil rights activist named Jack Weinberg set up a political table in the forbidden area in front of Sproul Hall. He was shortly confronted by the University administration in the person of Dean Murphy. The media was on hand, and Heirich managed to reconstruct much of the following conversation from radio station KPFA tape:

Murphy: Are you prepared to remove yourself, and the table, from university property?"

Weinberg (very quietiy): "I'm not prepared."

Murphy: "Are you aware that by not doing so you are subjecting yourself to probable disciplinary action?"

Weinberg (still more quietly): "I--uh--I'm aware that you're going to do what you'11 try to do."

Murphy: "Al1 right. Will you--uh--identify yourself?" Weinberg: "No."

Murphy (in a dead-pan voice, almost as if he were reading a script instead of talking to a particular person): "I must inform you if you are a student you are violating university regulations and if you are a non-student you are violating the trespass law. Will you identify yourself?"

Weinberg (even more quietly): "No, I will not."

Murphy: "You leave me no alternative but to ask Lieutenant Chandler to arrest you. Lieutenant Chandler, would you please arrest him."

Chandler: "You come with me, then, please."

Voices: "Take their place!" 
Weinberg, following classic civil rights tactics, did not either assist or resist the arrest, requiring that several officers carry him to a nearby police car. The police were careful to avoid provocative roughness in making the arrest in front of the now sizeable crowd of students attracted to the scene.

Within a minute about thirty students had seated themselves in front and in back of the police car containing Weinberg and the arresting police officers. In another brief moment, there were more than a hundred students sitting on the ground around the police car, effectively immobilizing it, and their numbers continued to grow.

In Heirich's careful account, "a number of persons claim to have been the first to sit down around the car." He describes the account of Richard Roman, a graduate student in sociology, as typical of a process that many reported going through as they made the sudden decision to defy authority. Roman reports himself as sympathetic to the students but not involved in the controversy at that point. He was crossing the plaza in front of Sproul Hall on the way to a luncheon date when he saw the police arresting Weinberg. He says, "I thought, 'It's a pretty rotten thing for the university to expel and arrest someone.' It made me mad to see the university pulling this trick to punish a few ... ." (quoted in Heirich, p. 151).

Roman reports that he thought at that moment of a tactic described by civil rights leader. Bayard Rustin to deal with a situation in which demonstrators believed that

. . the police were moving unfairly against an individual in an effort to intimidate the rest. Rustin would urge the group to confront the police as a unit, so that the latter would have 
to deal with all of them, rather than with just a few people.

At this point, Roman recalls, he spoke out, suggesting that people step into the path of the police, rather than getting out of the way. He had nothing specific in mind except to refuse to cooperate with this act by the police. After he made this suggestion, he was shoved by "a fraternity type" and got angry.

Roman yelled, "Don't move out of the way!" Shoving, the police pulled Jack Weinberg through the crowd to the car . . [Roman] ran toward the front of the car while the police put Weinberg in the car. He began yelling for people to sit down in front of the car, and some obeyed him. He ran around to encourage others to do the same, waving his arms to motion them down. A few other people were also urging others to sit down. For example, he noticed a graduate student, whom he didn't know by name but recognized as being from the same department, encouraging people to sit down behind the car (Heirich, pp. 151-152).

The police car was held for more than 24 hours while negotiations and student

were carried on by various faculty/intermediaries. Eventually, the demonstrators released the police car after student representatives and University President Clark Kerr signed a written agreement. The agreement called mainly for a set of procedures for resolving the issues in controversy, including representatives of the protestors as participants in the process.

The truce proved temporary, and the conflict built to a climax in which more than 7.50 people were arrested during the occupation of Sproul 
Ha11. This massive act of civil disobedience now appears as a watershed in the student movement of the 1960s, for it was soon to be followed by similar acts at many campuses across the country and in other parts of the world during the remainder of the decade.

During the same period, a social psychologist named Stanley Milgram designed a fabrication to explore a number of fundamental issues underlying obedience to authority. The paradigmatic situation that Milgram created involves a subject who is asked to administer what he believes to be an increasingly painful and, perhaps, dangerous series of electric shocks to an innocent victim. The person doing the asking plays the role of a psychologist conducting experimental work on how punishment affects learning. Milgram recorded many of the interactions between the participants on film. 2

We quote an example of these interactions:

"Next one," continued Vince, the naive subject playing the role of "teacher." "Short: sentence, movie, skirt, time. (After a pause): "Wrong. 165 volts. Time."

He delivered the shock and Mr. Wallace, the "learner," groaned. Vince laughed nervously. From inside the booth, Wallace shouted, "Let me out!" Vince looked over at the "experimenter," Mr. Williams, "That guy's hollerin' in there," he said quietly. "Continue please. Go on," the experimenter instructed. Vince sighed deeply. "Well, there's a lot of them here, you know. He's liable to have a heart condition there. You want me to go?" "Just continue, please." 
Vince turned back to his sheet, reading with authority, "Sharp: axe, needle, stick, blade. (Pause) "Wrong." Vince turned to the experimenter with alarm, "I'm up to 180 volts!".

Mr. Williams responded coolly, "Please continue, teacher."

Vince spoke into the microphone, "You're going to get a shock 180 volts." He pressed the switch.

Wallace cried out, "I can't stand the pain! Get me out of here!" Vince glanced over at Williams, "He can't stand it. I'm not going to kill that man in there. You hear him hollerin' in there?"

"As I said before, the shocks may be painful, but they're not dangerous," Williams intoned.

"But he's hollerin' he can't stand it. What if something happens to him?"

"The experiment requires that you continue, teacher."

"Yeah, but, heh, I'm not going to get that man sick in there. He's hollerin' in there. You know what I mean, uh, I mean, he's..." "Whether the learner likes it or not, we must go on until he's learned all the word pairs."

Vince jumped in, "I refuse to take the responsibility of him getting hurt in there. You know, I mean, he's in there hollerin.'" "I.t's absolutely essential that you continue, teacher." "Eh, there's too many of them left. I mean who's going to take the responsibility if anything happens to that gentleman?" "I'm responsible for anything that happens here," Williams emphasized. "Continue, please." Vince returned to his sheet, "Next one. Slow: Walk, dance, truck, musiç." 
These three incidents are examples of what we call "encounters with unjust authority". They are encounters in that they are strips of continuous, face-to-face interaction. They involve authority in that it is generally understood by all parties in the encounter that at least one party has the right and responsibility to regulate some aspects of the action: of the others. Somebody is operating in an authority role, typically as an agent of a larger authority system. Other participants expect to be subject to some form of attempted regulation. The degree to which participants eventually submit to regulation is treated as a variable element of an encounter with authority, but not as a defining condition.

What is the sense in which the encounters described above can be said to be encounters with "unjust" authority? We certainly do not mean that the people in authority roles are evil people. The shop foreman, Teefee, may have been arrogant in the encounter described, but he may also have been an exemplary citizen in general. Dean Murphy and officer Chandler were as polite as could be in carrying out their roles in the arrest of Weinberg, and there is no reason to think them less than sincere and honorable men.

Nor do we mean to assert our own moral judgments about these encounters as some sort of general standard for all to adopt. In defining the class of relevant encounters, we take the standpoint of the participants. To the extent that some participants share the view that the unimpeded operation of an authority system on a given occasion would result in an injustice, we consider the encounter relevant to our concern.

Note that the above definition distinguishes such encounters from those in which the unimpeded operation of an authority system will produce inefficiencies. It is not disapproval of authority as such but a partic-. ular kind of disapproval that makes the encounter relevant. An injustice 
involves the violation of some principle about what is fair - that is, it involves a moral dimension. ${ }^{3}$

It is reasonably clear in the encounters described above that many of the participants felt that the unimpeded operation of the authority system would result in an injustice. Many workers would have felt that the firing of the Perkins brothers and Joe Urban was unjust, regardless of whether they had acted collectively to oppose it. Many students and faculty at Berkeley would have felt that the arrest of Weinberg was unjust, regardless of whether they had collectively opposed it. Many of Milgram's subjects made clear that they had strong misgivings about administering such apparently severe electric shocks. Those who expressed this included both people who refused to comply and people who continued to comply. The individual or collective response to the operation of the authority system is treated here as the crucial variable to be explained rather than as a defining characteristic of encounters with unjust authority.

Authority systems are, as we know, capable of vast destructiveness and malevolence. Our daily newspaper provides us with countless concrete examples of governments that perpetrate injustice--injustice not only from our standpoint but from that of the governments' agents, subjects, and victims. How people mobilize to challenge unjust authority systems has long been a concern of social theorists.

Substantial challenges to authority systems generally involve considerable organization, resource mobilization, and struggle that extend far beyond what takes place in face-to-face encounters.: Yet encounters are frequently the occasion for important events in the life of sustained challenges. In the sitdown example, the encounter had consequences for the rapid growth of the United Automobile Workers. The police car capture 
was an important episode in the growth of the Free Speech Movement at Berkeley and in the student movement more generally. Collective action flowing from these encounters led to a substantial increase in the level of mobilization of the relevant constituency.

But some encounters have demobilizing consequences as we1l. Sometimes the solidarity of would-be rebels is undermined and the demoralization of a constituency is increased. Some encounters bring the forces of repression down upon the heads of challengers, frightening them into compliance and depriving them of crucial leaders.

Encounters with unjust authority, then, are potential episodes in the long-run career of a sustained, challenge to an authority system. What happens in such encounters has critical consequences for the mobilization of resources. To study such encounters is to study a problem in micro-mobilization: How do people, engaged in an encounter with unjust authority, move to varying degrees of rebellion and opposition?

\section{Contrasts among Encounters}

This paper describes and analyzes the MHRC encounter, a special case of encounters with unjust authority. Before presenting it in detail, we situate it with reference to several points of comparison among encounters. We briefly describe some of the distinctions among encounters that seem worth making and locate the MHRC case with respect to these distinctions. 
Individual vs. Collective. When : people with a similar relationship to the authority system confront its agents, response is heavily mediated by group processes. The solidarity or cohesiveness of participants, problems of coordinating common action, the degree of consensus about what is happening and what should be done about it, all take on major importance. Individual rebellion may carry on beyond the immediate encounter but collective encounters especially .... raise this specter. Collective rebellion presages the emergence of a collective entity that can sustain a rebellious state beyond the immediate interaction.

The MHRC case concerns a collective encounter with unjust authority. In that respect, it is more like the automobile assembly plant and Berkeley encounters than it is 1ike the Milgram encounter.

Continuing vs. Discrete. In some encounters, the participants have a history of previous contact and an expectation of future contact. The encounter occurs in the context of routinized, continuing interaction. In contrast, other encounters occur in ad hoc, nonroutinized settings. In a continuing encounter, potential challengers have established some pattern in their relations to this particular authority system. Perhaps it is a rebellious pattern, perhaps a compliant one, but in either case it provides a relevant context for the present encounter. Furthermore, there is an expectation of future contact that makes accountability for one's present actions a more salient issue in continuing encounters. The participants have to 
live with each other in the future. In contrast, the timelessness of discrete encounters frees the participants from many of these constraints. The MHRC case concerns a discrete encounter. In that respect, it is more. like the Berkeley and Milgram encounter and less like the auto assembly plant encounter.

Organized vs. Unorganized Challengers. The potential challengers in an encounter may be strangers, acquaintances, friends, kin, comrades, or some mixture of these. They may have an organizational infra-structure, or they may lack one. The encounter may be one they are anticipating or are deliberately seeking, and they may approach it with a detailed contingency plan. Or the encounter may be unexpected and approached with no prior planning or preparation.

In some encounters, the potential challengers are people who have been engaged in past political struggles and are operating within a well-coordinated organization. In contrast, the potential challengers may be composed of previously unacquainted individuals of heterogeneous background.

The MHRC case concerns a completely unorganized challenger. It resembles the Berkeley encounter in this regard and contrasts more sharply with the auto assembly plant. Although not highly organized, the workers in the assembly plant knew each other as co-workers, had formed some friendship networks, and were partially unionized. 4

Clear vs. Questionable Availability of Sanctions. The authorities in an encounter may have sanctions readily available either because they 
control such sanctions directly or because they can quickly procure them from other authorities with enforcement responsibility - if the need arises. In contrast, authorities may be isolated and vulnerable, lacking effective sanctions in the encounter and with questionable ability to call forth reinforcements if needed.

The authorities may approach the encounter with preparation and planning, including a detailed contingency plan for using forceful constraint if necessary. Or the encounter may surprise the authorities and catch them unprepared to deal with resistance or opposition.

The MHRC case concerns an encounter in which the agent of authority has no clear sanctions available. In this respect, it is like the Milgram encounter; and less like the auto-assembly plant or Berkeley encounters. In sum, the MHRC case is a collective, discrete encounter, in which unorganized potential challengers operating in agentic roles confront an authority with questionable sanctioning ability.

\section{The MHRC Situation}

We have chosen to study an encounter in which the agent of authority has no clear sanctions, although participants may vary in their perception of this fact. They may fear a sanctioning power that does not exist, but we attempt to minimize the issue of sanctions. By doing this, we are able to focus attention on the moral and psychological bonds that tie participants to authority systems, rather than on compliance that can be accounted for by inducements and constraints. Since we are interested in processes of initial group formation and organization as causal elements in rebellious collective action, we have chosen to study an encounter in which prior organization is absent.

The general features of the MHRC situation are that a group of strangers is hired individually by a large company to perform a vaguely 
defined task. They discover, after accepting the job, that the company is acting reprehensibly in their eyes, and they are asked to perform as lower agents of the company in carrying out its designs. The situation unfolds gradually and provides a number of points at which the authority requests specific acts of complicity.

More specifically, individuals in medium-sized towns in southeastern Michigan answer an advertisement to participate in research being conducted by a commercial research firm calling itself the Manufacturers' Human Relations Consultants (MHRC). They believe themselves to be participating, for a fee, in a group discussion of community standards. Typically, eight or nine people, of different gender and social class, convene in the conference room of a hotel or motor inn. The room includes videotaping equipment - 1ights, cameras, microphones, tape deck. After having them fill out a short questionnaire, the MHRC representative pays them \$10 as they sign a "Participation Agreement" which acknowledges that they were willingly video-taped, received payment, and that the tape produced is the sole property of the MHRC.

After participants have introduced themselves on camera, the coordinator explains the purpose of the session: to record a group discussion of a legal case in which a client of the MHRC is involved. The discussion is being recorded for use in this case which hinges on some issues of community standards, that is, "what people consider proper behavior".

The case is then described in moderate detail to the participants. The MHRC client, a large oil company, has terminated one of its service station managers, who is now suing them. He charges that he has .. been unjustly fired for criticizing major oil company pricing policies in a television "man in the street" interview and that the company invaded his privacy by hiring a private detective to investigate his off the job 
behavior. They claim they fired him because he is living with a woman out of wedlock, which violates reasonable standards for an employee who must deal with the public.

After a discussion in which very few participants spontaneously take the side of the company, the coordinator asks three members of the group to argue as if they are offended by the conduct of the plaintiff, Mr. C. After further group discussion and a break, an additional three people are asked to take this pro-company view. After an additional break, everyone is asked to make a summary statement from the viewpoint of a person offended by Mr: C's behavior.

Finally, participants are asked to sign a release form/affidavit which gives the MHRC permission to edit the video tapes for ease of presentation in court. If they refuse to sign this, the coordinator excuses himself to check with his supervisor and returns shortly to announce that he has been advised that the participation agreements which they signed at the beginning will be sufficient for using the tapes. He then proceeds to notarize the participation agreements and dismisses everybody.

The coordinator, if challenged at any point, has a scripted set of responses. At no time does he threaten the participants for non-compli-. ance or offer any inducements for compliance. The coordinator treats the participants as employees who have been hired to perform a specific task. He tells them what the job requires in a polite, straightforward, businesslike manner. No matter how resistant the participants are, the coordinator is never hostile or rude. Nor is he ever very friendly - no matter how cooperative they are. He is a supervisor, confident of his authority, dealing with a group of subordinates.

If the coordinator is asked to explain why some people are being asked to take the company's perspective, he suggests that the procedure 
will make for a livelier, more productive discussion with more points of view developed and considered. If participants refuse to accept this justification, he invokes formal authority by declaring:

Look, this is what the research calls for you to do. This project has been designed by professional researchers, and these are the procedures that have been established. My instructions here are quite explicit. Now we have to do. this research the way it's supposed to be done.

If participants refuse to accept this, the coordinator calls upon them to live up to their agreement to participate, to fulfill their contract with the MHRC, for which they have already been paid. If participants insist that what is being asked of them is wrong and unjust, the coordina-: tor assures them that the MHRC assumes full responsibility for any problems caused by the procedures. If resistance still continues, the coordinator makes one final effort to gain compliance by.-reiterating that the research is designed by competent professionals, that they have agreed voluntarily to participate and have been paid for it, and now have an obligation to complete the job. He rejects any efforts by participants to return the money they received. 
Rebellious Collective Action

The MHRC fabrication is a good deal more complex than the one confronting Milgram's potential challengers. Milgram deliberately confronted people with a clear stimulus situation: they recognized that their actions were causing pain to another person. He attempted to frame the situation unambiguously for his subjects. The MHRC encounter, in contrast, requires a more active, interpretive process on the part of potential challengers.

Encounters are characterized by certain assumptions, usually shared, about the rules that govern them and define appropriate behavior. The MHRC encounter presents the participants with a complex and subtle problem of collective definition and interpretation. Before potential challengers can move to collective action, they must adopt a common frame about what is happening. The relative complexity of the MHRC encounter enables us to observe how the process of collective definition operates and how it relates to rebellious collective action.

While a simple dichotomy between compliance and non-compliance may be sufficient for:some purposes; it obscures the complexity of the alternatives available to participants and the process of moving collectively to rebellious action. We distinguish five categories of action that participants can engage in by themselves or with others.

1. Compliance. Participants are acting in role in : : an authority system. They are carrying out the requests of an authority to the best of their ability, frequently attemp.ting to demonstrate their competence in the process. They may ask questions of the authorities, but these are designed to clarify their instructions rather than to request justification of procedures.

2. Evasion. Participants do not confront the authorities, but they do not perform in the correct or desired manner. Like the Good Soldier 
Schweik, they are apparently compliant, but, in practice, their performance is marred by error from the standpoint of authorities. They attempt to avoid surveillance so that a confrontation can be avoided. Any failure to comply is implicit and not openly acknowledged by the participants.

Face-to-face encounters may make such evasion difficult as a stable strategy. Some of Milgram's subjects tried to cue the "learner" whom they were shocking by emphasizing the correct answer as they read the list of words to choose from. This proved totally ineffective, since the "learner" was, in fact, a confederate of the experiment. However, when the experimenter relayed instructions over the telephone and there was no direct surveillance, this evasion strategy became much more feasible. Many subjects failed to increase the shock level as instructed without acknowledging this fact. This gives us good reason to expect that evasion would have been a more widely used alternative in Milgrams's encounter if his design had permitted it as an effective possiblility.

3. Dissent. Participants publicly express objection to the way in which authorities are acting, by in some way criticizing or denouncing them or their behavior. We include here also demands for justification of procedures which imply criticism. The intensity of dissent may vary from participants politely expressing doubts about whether authorities are acting properly to harsh denunciations of them.

Milgram wisely recognizes the subtle nature of dissent as a challenge to an authority system:

Dissent refers to a subject's expression of disagreement with the course of action prescribed by the experimenter. But this verbal dispute does not necessarily mean that the subject will disobey the experimenter, for dissent serves 
a dual and conflicting function. On the one hand, it may be the first step in a progressive rift between the subject and the experimenter, a testing of the experimenter's intentions, and an attempt to persuade him to alter his course of action. But, paradoxically, it may also serve as a strain-reducing mechanism, a valve that allows the subject to blow off steam without altering his course of action. Dissent may occur without rupturing hierarchical bonds and thus belongs:to an order of experience that is qualitatively discontinuous with disobedience (1974, p. 161).

4. Resistance. Participants openly refuse to do what the authorities ask them to do. This differs from evasion in that the noncompliance is complete, open, and acknowledged. Whereas evasion involves slyly botching the performance of a role, resistance involves breaking out of the role altogether.

Acknowledgment of non-compliance forces the authority to respond in some fashion. The authority may explicitly ratify the non-compliance by withdrawing the request for compliance or implicitly ratify it by making no effort to enforce or repeat the request: Usually, however, participants who sustain resistance must withstand the pressing of demands for compliance by authorities accompanied by implicit or explicit threat of sanctions for non-compliance.

5. Struggle. Participants take action aimed beyond the encounter 
to stop the authority system from perpetrating the injustice. Participants may try to persuade countervailing authorities to constrain the unjust authority or undo him altogether. Or, they may plan to mobilize resources to deal with the unjust authority in other ways. Struggle goes beyond noncompliance and pro-actively seeks to change the authority system through efforts that reach past the end of the encounter.

This category. is ignored by Milgram but is of prime importance in linking encounters to sustained mobilization efforts. Even collective resistance by one group will have little impact if there are other groups of people to take their place in line. Refusing to act as the agent of an unjust authority may save: one's individual conscience, but the authority system may be able to obtain other agents to do its work.

Struggle represents a critical level of action beyond resistance. It could have been manifested in the Milgram encounter by participants not only refusing to continue but making efforts to prevent the research from continuing. One obvious channel for such efforts is public exposure by going to a newspaper to rally public opposition or going to Yale University officials in an effort to get them to exercise benign authority in discontinuing the research. Milgram did not apparently ask those who refused to comply whether they planned to take further action after leaving the laboratory, but, prior to being dehoaxed, some of them may well have intended to.

\section{The Difficulty of Challenging Authority}

The agentic role is an extremely difficult one from which to launch an attack on authority. There is a series of forces that hold one in 
role, making compliance the natural state. Milgram argues that there is a tendency for those in such a role to develop a particular mental set or state of consciousness that he calls the "agentic state." It is a condition a person is in:

- . when he sees himself. as an agent for carrying out another person's wishes. This term will be used in opposition to that of autonomy--that is; when a person sees himself as acting on his own . . . A person entering an authority system no longer views himself as acting out of his own purposes but rather comes to see himself as an agent for executing the wishes of another person. Once an individual conceives his action in this light, profound alterations occur in his behavior and his internal functioning (p. 133).'

This state of consciousness, Milgram suggests, removes from the individual the sense of responsibility for his own actions. As an agent of another's.will, one is no longer choosing but simply carrying out a set of well-defined expectations. Participants who are fully engaged in an agentic role have a difficult time even conceiving of the possibility of rebellion. They must break out of this way of framing the situation and the role behavior appropriate to it before rebellious action can occur.

Just how compelling such a state is depends on the nature of one's role in the authority system. Engagement is likely to be highest for agents such as managers or enforcers, somewhat less for agents such as 
employees or subjects, and weaker still for those in general public roles such as spectator. Nevertheless, even agents in an MHRC encounter find a series of strong forces operating to hold them in role:

1. Self-Interest. Self-interest is a proven political motivator. One might well expect that the primary concern of MHRC participants would be to cover their own rear. In fact, many different aspects of self-interest combine to hold people in the agentic role:

First, there is the issue of sanctions. Although the coordinator never threatens participants, we went to some lengths to make the MHRC appear rich and powerful. Potential challengers might well have regarded it as a formidable opponent to attack, one that is able and willing to pursue an adversary with legal sanctions, for example. The MHRC presented a public front of a large national corporation with its main office in Dallas, Texas and a branch in southeastern Michigan, the largest firm in the country performing marketing and personnel services for industry. As long as one complies, there is no danger of negative sanctions, but a challenger faces some possible retaliation. The very uncertainty may encourage diffuse and irrational fears in this regard.

Second, an ethic of minding one's own business helps to maintain 
the agentic role: In the MHRC encounter, Mr. C is unknown to the participants, a distant victim of the MHRC's oil company client whom they will never need to look in the eye. "Distance, time and physical barriers neutralize the moral sense," Mitgram writes (1974, p. 157). If potential challengers remain in the agentic role, they will be contributing to an injustice at a great distance. It is a far cry from pressing a person's hand onto an electric shock grid as Milgram's subjects were asked to do in one variation. There is little in this situation to propel them to take uncertain personal risks in opposing the MHRC when they can easily enough go along without ever having to face the direct consequences.

Third, there is the fact that preventing an injustice to $\mathrm{Mr}$. $\mathrm{C}$ is a collective good. Potential challengers are told that many groups of people are holding similar discussions of community standards. If they personally refuse to comply with what the authority asks, it will have little if any effect on the outcome of Mr. C's case. On the other hand, if others succeed in attacking the MHRC and preventing the injustice to $\mathrm{Mr} . \mathrm{C}$, they will have gained the benefits without taking personal risks. Either way, nothing is gained personally by risking an unpleasant scene and perhaps even possible sanctions.

2. Obligations to Legitimate Authority. It is important to recognize, as Milgram does, that authority systems exert their own moral claim for compliance. When authorities are regarded as legitimate and acting within their domain of responsibility, the agentic role makes a moral claim on the incumbent. As Milgram puts it, the moral concerns of a person in such an encounter focus on:

-. how well he is living up to the expectations that the authority has of him. In wartime, a soldier does not ask $\cdots$. 
whether it is good or bad to bomb a hamlet; he does not experience shame or guilt in the destruction of a village: rather he feels pride or shame depending on how well he has performed the mission assigned to him (1974, p. 8).

Authorities typically operate with a presumption of legitimacy. The authority in the Milgram encounter was buttressed by the legitimating ideology of science. This ideology was institutionally embedded in Yale University, but the presumption of legitimacy was apparently still operating in his Bridgeport version. In this variation of his basic fabrication, Milgram invented a fictitious organization calling itself "Research Associates of Bridgeport," which conducted the experiment in rented offices in a commercial building in the downtown shopping area of Bridgeport.

Even such fictitious entities as the MHRC and Research Associates of Bridgeport seem able to operate on a presumption of legitimacy that allows the authority to make a moral claim on participants. The fact that the potential challengers have voluntarily agreed to participate induces a sense of commitment and obligation that operates as a force to keep them in the agentic role.

3. Face-Work. Encounters with authority are a special case of encounters more generally, and there are factors operating in all face-toface interaction that restrain challenge: Goffman (1959) has done the most to make us aware of such factors. Every social situation is built upon a working consensus among the participants. One of its. chief premises is that once a definition of the situation has been projected and agreed upon by participants, there shall be no challenge to it. Disruption of the working consensus has the character of moral transgression. Under no circumstances is open conflict about the definition of the situation compatible with polite exchange. 
When an individual projects a definition of the situation and then makes an implicit or explicit claim to be a person of a particular kind, he automatically exerts a moral demand upon the others, obliging them to value and treat him in the manner that persons of his kind have a right to expect (p. 185).

Milgram, describing some of the factors that hold a participant in the agentic role, includes "politeness on his part, his desire to uphold his initial promise of aid to the experimenter, and the awkwardness of withdrawal" (1.974, p. 7). Most people, it seems, don't like to create a scene, and a challenge to authority will do just that. It will necessarily disrupt the smooth flow of interaction and will perhaps lead to an awkward and unpleasant interpersonal exchange. Face-work considerations, then, operate to keep the participants functioning in the agentic role.

4. Reification. Authority systems are products of human control, but this is sometimes forgotten by those who participate in them. Milgram calls this reification process "counter anthropomorphism":

For decades psychologists have discussed the primitive tendency among men to attribute to inanimate objects and forces the qualities of the human species. A countervailing tendency, however, is that of attributing an impersonal quality to forces that are essentially human in origin and maintenance. Some people treat systems of human origin as if they existed above and beyond any human agent, beyond the control of whim or human feeling. The human element behind agencies and institutions is denied (p. 8).

There is one aspect of the MHRC encounter that may particularly encourage such reification. The coordinator responds in ways that imply 
that he is an agent of a larger system in which he is but one cog. For example, when pressed on the procedures, one of his responses is to assert that the "project has been designed by professional researchers, and these are the procedures that have been established. My instructions here are quite explicit." Potential challengers might well feel that the coordinator and they are all participants in some external entity over which none of them has any control. Reification, then, is another force to maintain the agentic role.

Breaking out of the agentic role is only half the battle in mobilizing for rebellious collective action. Even without the agentic role, it is no easy task for a group of previously unacquainted people to organize themselves for an attack on authority. The MHRC encounter confronts participants with a problem of interpreting a complex set of unfolding events. It is not always clear how others have interpreted what is happening, and it is difficult to arrive at a shared alternative to the working consensus which the authority has imposed.

Nor do they have any previous experience working together on a common task. They have no established working relationships or hierarchy of leadership that would ease the problems of coordinating action. They do not even think of themselves as a group, but as a collection of individuals with the flimsiest of common bonds. To embark on rebellious collective action with such a haphazard group of shipmates is likely to seem foolhardy to many. They do not know to what extent they can count on their fellow participants should a storm develop, and they have no way of finding out until it may be too late to turn back.

\section{Responses to the MHRC Encounter}

Between the difficulty of eluding the agentic role and the difficulty of strangers organizing themselves, rebellious collective action might well 
seem improbable in the MHRC encounter. In fact it occurs frequently and in various forms. In this section, we summarize the responses we observed in 33 iterations of the MHRC encounter. There is considerable variability among the 33 groups. This is not surprising, since we intended to produce variability and deliberately altered the conditions under which some of the groups were run. ${ }^{5}$ Participants, faced with a difficult situation, improvised in various ways, some of them quite ingenious. From our present vantage point, we can see pattern and order in these responses, but the encounters, as events, were extremely rich and idiosyncratic.

Eventually, we hope to account for some of the differences among groups with a systematic analysis of the questionnaires and video-tapes that comprise our data set. Since data reduction and analysis is still in progress, we prefer to limit ourselves at this point to a summary description, ignoring important differences among groups that might account for variation. We will also omit the methodological and procedural details that a reader would need to evaluate the quality of the data we present and how well we met our obligations to participants.

All of the 33 groups settled into role without difficulty. All of the 261 participants obediently completed our questionnaires, introduced themselves to the camera as asked, and began a discussion of the case as asked. All except one group signed the participation agreement in which they acknowledged that they were willingly videotaped, received payment, and that the tape produced was the sole property of the MHRC. The resisting group followed the lead of a retired book editor from a local publishing house who suggested that he never signed anything in advance. The exchange was polite and reasonable, but this unusual response foreshadowed later fireworks. Even this group complied willingly enough with the remainder of the coordinator's benign instructions. 
The coordinator's first transgression occurs when he asks one-third of the participants in each group to "argue as if you were members of the community who are offended by Mr. C's behavior." At this point, the groups diverge significantly. In sixteen of the 33 groups, more than one-third of the group members either publicly registered an explicit protest against this procedure, or publicly refused to comply with it. The people registering dissent or resistance were not restricted by any means to those who had been asked to give false opinions.

In two of these sixteen groups, dissent became general resistance, . and the coordinator was unable to gain sufficient compliance to proceed. A description of one of these scenes provides a richer sense of the inter-: action at that point:

Mr. Rytina, the coordinator, entered the room, turned off the tape deck, and approached the group: "That was fairly lively there, and I think we can move on to the second question. But for this question, we're going to make an adjustment in the procedure here. What we're going to do on this question is we're going to ask Dick, and Linda, and Jean - this has been done by a random procedure - to take the point of view of someone in the community who's offended by Mr. C's behavior. Carl interjected, "Would you mind leaving the tape on while you say this?"

Rytina responded, "Well, this is standard procedure here." Carl repeated, "Would you mind leaving the tape on while yougive us these instructions, so that it doesn't appear . . ." "That's not what my instructions call for me to do," Rytina interrupted. "That would be, I guess, a waste of tape. But 
I certainly. . . I just follow the instructions."

Carl sounded incredulous. "You're telling somebody to pretend, and you're gettin' a video-tape of them pretending, but you're not puttin' on the tape that you're tellin' them to pretend?"

"If you noticed what happened here in this first discussion, it was largely the case that most people were on the same side. And we found in the past that you can get a much more lively and fuller - discussion if there are some differences of opinion within the group. And so we're asking these three people to take the point of view of someone who's offended by Mr. C's behavior, so we can get a livelier discussion." The group stiffened during Rytina's attempt to justify the procedure. Linda and Frank exchanged looks of disbelief, then Frank looked away and slowly shook his head. Linda stared at the coordinator, her mouth agape. When Rytina finished his statement, members of the group who had previously been silent jumped into the fray. Over the angry murmurings of several people, Frank interjected, "But if that's not. a point that they . . " Linda insisted loudly, "I don't feel that way. If I don't feel that way, I'm not going to act like I do! Especially on the tape!"

Rytina began to stumble. "Well, no, it's not... now, it, it, it's really . . I'm sure you'1l find that it's first quality. It's much easier to do when you make an effort to just sit and think for a minute..."

Linda looked at Carl: "I'm not going to act in some way I don't feel." 
Rytina persisted, "There are people like that in the world who feel that way, and we're asking you to act as if you feel that way."

Linda looked away, shaking her head in disgust. The other group members sat silently, eyeing the coordinator. Rytina continued, "And you'11 see, if you try that, how much livelier the discussion gets, and how much better this whole thing will work then."

Various group members began to mumble inaudibly among themselves. Having regained control of the floor, Rytina finished his instructions. "So let me ask you to try that, okay? And we can move into the second question, and if you three people will take the point of view of someone offended by Mr. C.'s behavior. . ."

He then left the room, turning on the tape deck as he exited. Rebecca pronounced triumphantly, as the coordinator departed, "This, ladies and gentlemen, is what Watergate is all about." The group roared with laughter.

Linda leaned back in her chair, still smiling, and asserted, "I'm not going to say anything."

Frank mumbled, "I mean, I'11 take the money, but this is the most ludicrous afternoon:. . ." Rebecca agreed, "I think we should object on principle." Randy added, "I know one thing: it's against my personal thing to try to, uh, go against my own ideas."

The coordinator never does succeed in getting this particular group to comply, and before the afternoon is over, the group becomes highly mo- 
bilized for struggle against the MHRC. But in 31 of the 33 .groups, in spite of strong public dissent in 14 of them, the coordinator does get sufficient compliance with his instructions to proceed.

In some of these 31 groups, compliance was ambiguous at best. People evaded the task, giving sarcastic or exaggerated responses. In one group, a participant doing his best to sound like Gabby Hayes intoned, "Next to ma waaf, ma car is ma favritt thang, an' ah ain't sending neither of 'em tuh thet gas stoishen." Another group member followed his comment with her own serious but still only half-compliant statement, "Well, I feel that if, um, you're a public servant, and you're working for a company that you're in the public eye all the time. Then I suppose that you do have the obligation to uphold certain standards. But I also do not agree with violation of private rights. I want that made clear."

In many groups, compliance was substantial. Those who hadn't been asked to give false opinions sometimes offered suggestions and assistance to those who were attempting to comply. In most groups during this phase of the encounter, participants reacted on an individual basis, and sometimes tension was apparent among group members following different strategies. In a few groups, participants oscillated dramatically, advocating resistance with one breath and compliance with the next. Throughout this period, resistance and protest became more prevalent in all groups, but this progression was typically halting and irregular.

The final scene before presenting the participants with the affidavits has the coordinator asking everyone to make a summary statement supporting the oil company. By the end of this scene, 29 of the 33 groups have had one-third or more dissenting or resisting at some point, and 14 of these had two-thirds or more dissenting or resisting in this particular scene. Some confrontation between the group and the coordinator was typ- 
ical at this point.

Given the earlier history of the encounter, the presentation of the affidavit for their signatures is a moment of considerable tension in many groups. The affidavit states:

I hereby permit the Manufacturers' Human Relations Consultants to utilize video-tapes of a discussion in which I participated on this date. During the discussion, I was aware that my comments were being recorded. Further, it is understood that such tapes will be submitted to the United States District Court for the Eastern District of Michigan, Southern Division, in conjunction with an amicus curiae brief, and that the tapes will be edited in such a way: as to facilitate their presentation to the court.

It takes a moment for the implications to sink in. The silent reading of the affidavit was often punctuated by gasps, sighs, and expressions of dismay and anger. Some groups reacted immediately and angrily, ripping up their affidavits and greeting the coordinator with a storm of protests. Others were slower and less unanimous in their reaction. In some, the affidavit set of $\mathrm{f}$ heated discussion about the appropriate response. In one group, the most compliant of all the 33 , even this provocation was accepted passively as all signed.

The coordinator was confronted with complete. resistance in 15 groups: no one signed the affidavit. Six groups were equally unanimous in compliance while the remaining 12 groups divided. ${ }^{6}$ Even in groups where signing was common or consensual, there were often people who said initially that they wouldn't sign, although they eventually did. There is clearly an important difference between groups that presented a united front of 
resistance and those that did not. But most of these latter groups were far from passive.

To what extent did these groups move beyond resistance toward action aimed beyond the encounter and designed to stop the MHRC from perpetrating injustice. We looked for mobilization for such struggle in such specific actions as:

\section{Intention to Conduct Further Investigation. Participants fre-} quently discuss going to a newspaper, a lawyer, the Court, the Better Business Bureau, or other officials to report on what they have experienced. It is usually quite clear in these discussions that the participants hope to expose the MHRC to public or official view as an evil outfit. Thus, it can be construed as a planned attack on the MHRC. The following exchange provides an example:

Jack started gathering materials from the table and folding them up. "I'm going to take these things over to the News right afterward. I'm going to talk to an editor."

Leif liked the idea. "Have them publish something about this, so they don't sucker more people into it."

"Go to the News! Go to the News!" agreed Chuck. "Can we all go to the News together?" another participant asked. "Oh, sure," said Jack.

"Yeah, it's probably a good idea," Leif reacted, "so they know . . ." 
Organizing. If participants are to act as a group in pursuing an attack on the MHRC, they must take a few necessary steps for such future action. These minimal steps involve a capacity to reassemble as a group. We look for any of three indicators of such organization: the planning of a meeting at some other place, the exchanging of addresses and/or phone numbers, and the employment of some division of labor among future tasks (for example, one person calling a lawyer, another person calling the newspapers).

We consider 15 of these groups highly mobilized for struggle at the end of the session. They score on more than one of the above indicators, and their discussion and planning are more or less continuous at the end and involve most of the group. In the other 18 groups, there are sporadic or isolated, individual acts, but not sustained group discussion of how to attack the MHRC.

Chart One presents the basic description of the pattern of response in the 33 groups. There are several noteworthy features revealed in it. (Chart One goes about here.)

First, there are two particularly common streams. One of these runs through high early protest and ends in complete resistance to the affidavit and a high likelihood of mobilizing for an attack on the MHRC. The second of these runs through low early protest, leads to substantial later dissent but ends in some signing of the affidavit and a relatively small probability of mobilization for struggle. 
Tables One to Three help make the pattern even clearer. First, there is a clear relationship between resistance to the affidavit and struggle. As Table One shows, a group that has been able to unite behind complete resistance to the coordinator is an excellent bet to go on to mobilization for struggle. Seventy-two percent of them mobilize compared to only 18 percent of the groups that fail to sustain unanimous resistance to the affidavit.

(Tables One to Three about here.)

Table Two shows that it is early protest rather than later protest. that is critical for predicting which groups will resist the affidavit. Curiously enough, late protest is unrelated to affidavit resistance, and the pattern does not even run in the expected direction. Table Three makes it clearer why this is so: there is no relationship between early protest and protest in the later scenes. One might well think that dissent that is more proximate to the presentation of the affidavit would be predictive, but this is clearly not so. The coordinator's first transgression turns out to be a critical moment.

$\underline{\text { Breaking-Out and Getting Mobilized }}$

The movement from engagement in the agentic role to a state of rebellion requires breaking through the constraining factors described earlier. But an aggregate of individuals in a rebellious state is not yet a collective actor. The individuals must have at least some nascent organization that makes it possible for them to act as a unit. Both breaking-out of the agentic role and creating a collective actor are formidable tasks. Rebellious collective action is not an everyday occurrence. But it occurs often enough to suggest that the problems are far from insoluble.

This is clearly true for the MHRC encounter. Some groups are able 
to cast aside the agentic role and to master the organizational problems of acting together quite rapidly albeit with considerable stress. Others move indirectly and unevenly but manage to arrive at the same point. Still others are unable to break-out, or falter on the rocks of internal division.

What is the process by which some groups manage to become mobilized for a collective attack on the MHRC? It is useful to think of a set of simultaneous processes rather than a single one. As the interaction proceeds, the potential challengers change in their collective definition of what is happening, in their internal relations, and in their relationship to the coordinator. Success in mobilization results from these changes.

Ultimately, we expect to ground our arguments about the nature of these processes and their importance for producing rebellious collective action in the analysis of the MHRC data currently in progress. At this point, we offer our tentative thinking.

The Participants Frame. 7 Participants enter the MHRC encounter with some vague beliefs about what is happening and what to expect. Once the coordinator enters the scene, he introduces a working consensus which we will call the task frame. This frame defines the situation as one in which there is a job to be done. The coordinator's responsibility is to provide the other participants with instructions, and it is their job to carry out these instructions as best they can. Appropriate behavior means getting on with the job.

Acceptance of this task frame means remaining in the agentic role. But this frame has a built in vulnerability to challenge: it allows questions. A completely appropriate question, from the standpoint of the 
task frame is a request for clarification of instructions. But this opening can be exploited by directing questions to the rim of the encounter--that is, to the social context surrounding it. In this instance, such questions concern who the MHRC is and what its purposes are.

The coordinator, however, is prepared to parry these questions and direct the group back to the task frame. He can be defeated in this, but it takes persistence and group support to keep pressing rim discussion. Sometimes an impasse is broken by one of the participants resuming the task, thereby reinvoking the coordinator's frame. This is almost always sufficient to end rim discussion for the moment.

For rebellious collective action to occur, the group must adopt an alternative to the task frame, one that supports an attack on the MHRC. This alternative frame is predicated on the belief that the unimpeded operation of the authority system will result in an injustice. Its general outline is clear enough in the MHRC encounter: that the MHRC is ordering the participants to misrepresent their opinions in order to help a large oil company win a legal case against a local gas station manager who spoke out against high prices.

How do groups manage to gain a commitment to this alternative frame? It is important for potential challengers to establish rim discussion at the coordinator's first transgression. It takes imagination, quick thinking, and courage for participants to have the presence of mind to challenge so early. They must respond rapidly to unanticipated behavior and immediately recognize the discrepancy between the coordinator's request and the rim presented. There may only be a brief moment in which the traffic rules of interaction allow one to insert a question or comment. Almost immediately, some participants may begin complying, giving the task frame renewed mementum. 
But there is no reason why all participants need to seize the momemt. One exemplar or leader with the presence of mind may tentatively begin a line of questioning that is picked up by others and soon develops into an alternative frame. If the alternative frame is not immediately accepted by everyone, at least it has been established as a competitor to the one offered by the coordinator.

When a participant successfully engages the coordinator in justifying what is happening, this person is implicitly asserting the right of group members to participate in the definition of appropriate behavior. This assertion frequently sparks others to demand similar rights and this genie, once out of the bottle, is difficult to put back. The more that discussion and argument centers on the nature and purposes of the MHRC, the worse off the coordinator is in maintaining his fragile task frame.

Groups may succeed in sustaining a rim discussion, but they are likely to drop back into compliance if unable to articulate an alternative. In some groups, the articulation is fragmentary and incomplete; it is implied by the participants' questions rather than explicitly asserted. However, in groups that eventually mobilize for struggle; the articulation of an alternative frame is quite explicit as in this example from the early resisting group quoted above:

"These are the procedures . . ." began the coordinator, Rytina.

"That's illegal . . That's illegal!" shouted Rebecca.

The coordinator bulled his way forward. "These procedures have been designed by fully competent professiona1s."

"Designed!" Linda retorted. "That tape didn't even show that you were asking me to pretend." 
Carl jumped in, "Do these professional people

know that what you're in fact doing is suborning perjury? . . ."

After some ensuing discussion, Carl cast his eyes down and began calmly, "What's exactly the matter with this country, man, is that people are into sellin' their points of view, they're into keepin' their mouths shut; they're into sayin' what they don't mean--for money. I ain't going to do it."

The task frame operated to suppress rim discussion and, thereby, reduces the opportunity for articulating the alternative. But the participants are provided with special opportunities for rim discussion in two scenes where they are given short "breaks." These scenes are important precisely because of their exemption from the task frame. It is not necessary to challenge the working consensus established by the coordinator in order to hold rim discussion since group members are free to talk about anything they want. Group support in a more limited sense is still required, since a participant may introduce a rim question only to find that others change the subject--but such support is much easier to obtain when it doesn't involve challenging the task frame in a confrontation with the coordinator.

It is striking that the groups which reach complete resistance don't really need the breaks. They force a rim discussion and register public dissent against the MHRC procedures at the coordinator's first transgression, before the first break scene has even occurred.

When the break scene occurs it can be utilized to move further. The groups that dissent early already have a significant accomplishement. The successful rim discussion and public objections to MHRC procedures are a 
matter of general knowledge. It is now a public matter that several members of the group believe that the MHRC is, to say the least, untrustworthy. Recognition of this belief remains part of the group's frame even when individuals return to the coordinator's task. The subsequent break allows the group to move on from a discussion of what is happening to a discussion of what to do about it.

Other groups, unable earlier to get free of the task frame, are unable effectively to utilize the opportunity provided by the break scenes. To be sure, progress is made in these scenes. Rim discussion is frequent and the group members move toward establishing an alternate frame. However, they must sometimes deal with tensions that have developed as individuals pursue different strategies for coping with the encounter. Some members have already become complicit in varying degrees and have acquired a subtle stake in maintaining the legitimacy of the task frame as a justi- $\ldots \ldots$ fication for their earlier compliance. In sum, the usefulness of the break depends on the prior state of readiness of the group. It has the potential to sharpen the division between the potential challengers and the authority, but it also has the potential for sharpening internal divisions in the group. 8

Internal Relations. The participants are strangers to each other when the encounter begins. They have little in common and possess no collective capacity for action. Yet some of the groups are able to mobilize to the point of attacking the MHRC.

To achieve this the group members must be able to create an alternative structure that can serve as a vehicle or carrier for collective action. This nascent movement organization has two important features of an alternative authority system:

1. It provides some mechanism, however informal, for selecting courses of action. The mechanism may be one of individuals following the lead of some exemplar, or a consensual line of action arrived at through discussion. In either case, the group is able to make collective decisions. 
2. It exerts a claim on group members for treating its courses of action as binding. The presumption of compliance that was initially held by the coordinator in the MHRC encounter shifts to the group. When the group selects a line of action, the individual members feel some obligation to support it even if they are not fully convinced of its desirability.

The basis of the group's claim on the individual is not hierarchical. It does not rest on the claims of the agentic role but on a web of voluntarily accepted and shared obligations. The agentic role may come in time if the nascent organization turns into a formal one, but at this stage, its claim for support is consensual. It stems from the implicit commitments that individuals have spontaneously made through pursuing a line of behavior in the encounter.

How do groups create such nascent organization? One can get a glimpse of this process in operation in the encounters described in the beginning of this paper. "Come on, fellows, don't let them fire little Joe," Simons shouts to the other members of the assembly shop. There is an appeal here to an identifiable constituency and the appeal has a moral imperative. Simons is out on a limb. If little Joe can be dragged off and fired without any collective response, Simons' own' job is certainly in danger. One can imagine how deflating it would be to the nascent organization if everyone watched in silence as little Joe was led away. Passivity is a rejection of the implicit claim of obligation in Simons' shout.

In the Berkeley encounter, Dick Roman directed similar shouts to the crowd: "Don't move out of the way." Those bystanders within the sound of his voice were the constituency in this case and one can note a significant difference here: the bystanders are not in an agentic role. They are looser and more available for mobilization than are the auto- 
workers or MHRC participants. But the appeal to them has the same moral imperative: Roman was taking risks and even encountering opposition in his shouting. The police might suddenly decide to arrest him for creating a public disorder. The bystanders faced a stark choice of standing by and rejecting the moral claim or responding to it by supporting the call for collective action. In this case, they did not heed this particular call but responded moments later to similar appeals to sit down around the police car.

Part of this process is clearly the development of a sense of group loyalty or solidarity. Engaging in common political struggle is an important mechanism for creating it. Early dissent and resistance in the MHRC encounter are particularly important in this regard. The participant who begins dissenting or resisting is the point man in a potential challenge. Keynoting the interaction in this way one is vulnerable to repudiation by the group, isolation, and retaliation by the coordinator. Risk taking on behalf of the group asserts a moral claim. If others respond to that claim by joining in support of the challenger, an important solidary bond is created. The more this process continues and becomes general, the stronger the sense of comradeship that develops. The result of this development is a sense of loyalty and a willingness to abide by the commitments that the group makes.

Early internal disagreement can be equally devastating to the development of a nascent organization. One or two individuals publicly repudiating the claims of a challenger can be a very harsh blow when the claims are still at such a fragile and delicate point. If support on a risky course creates a positive bond, rejection on such a course creates a similar but antagonistic bond. 
One way that groups avoid such a fiasco is by a careful process of testing the water before jumping in. They check each other out to gain a sense of firmness and reliability of commitments. They observe what others say and do as the interaction unfolds and gain a sense of who is ready to support what stances in the interaction. We do not mean to suggest that this is a conscious process but we do believe that the participants are tuning in to many subtle cues, verbal and nonverbal, that suggest who can be counted on and to what extent.

If this process is to move forward, some members of the group need to take risks by committing themselves to a public line of challenge before they know whether they will receive backing from the group. Some do this cautiously so they can draw back easily enough in the absence of support. But as members show increasing verbal commitment to an alternative frame, challengers grow bolder. Those who are keynoting the interaction with the coordinator in this process are committing the group to a line of action. At various points, members are faced with a stark choice of either supporting the nascent organization by following its line or supporting the authority system that the challengers are attacking by complying with the coordinator. Everytime the nascent organization passes such a test it grows in strength but every test also presents the peril that some group members will repudiate it.

A nascent organization frequently develops through a process of accretion. A sub-group of challengers forms and gradually wins adherents until it includes the entire group. More moderate group members who earlier sought common ground between the coordinator and the rebels sometimes join the rebellion in the later stage and even assume leadership roles in confronting the coordinator on behalf of the group. 
A nascent organization, then, must have generated some loyalty from group members and found some way of managing internal conflict. But no amount of solidarity tells a group what must be done and how to do it. Someone must lead the group to an action it can take to thwart the authority system. People must figure out where and when the group can meet if the course of action calls for such a meeting. They must figure out how to get in touch with each other if the group's plans require it.

These are mundane tasks and yet planning for struggle seems to call forth great energy and euphoria. United resistance is a heady experience itself, but at this point the group is still in a state of considerable tension as it maintains a tenuous relationship with the authority. Moving on to attack the MHRC breaks this tension. Energy seems to be released in this process as the group finds a purposeful direction.

What is the source of the energy and euphoria that has so often been reported in accounts of rebellious collective action? In traditional collective behavior thinking, the euphoria is a product of negative and pathological features of groups process: deindividuation, diffusion and blurring of individual responsibility, short-circuiting and oversimplifi- $-\ldots$ cation, scapegoating, or even an irrational group mind.

In contrast, we see it as arising from a process of affirmation: solidarity in struggle affirms the participants' principles of justice and their sense of themselves as people who can defend their principles. Such affirmation is heightened by relief when struggle marks the end of indecision, evasion, doubt about the group's capacity to act together, 
and fear of repression. The more that the participants had been troubled by the injustice, the more they are relieved by the prospect that they can stop it. As they overcome the barriers to mobilization, they experience the heady sense that they have taken a decisive step and seized control.

A key issue among different perspectives on collective behavior is how the enthusiasm we discuss is related to a group's capacity to cope realistically with its problems. In the classical perspective, euphoria arises from a process in which participants are swept away by false fears, and then false hopes, based on beliefs that oversimplify and dramatize the nature of their problem and its solution. It arises in struggles that have symbolic richness but little efficacy.

But, in the MHRC situation we find that enthusiasm may be generated by reasonable definitions of the situation and practical suggestions for struggling aginst the authority. And once generated, enthusiasm contributes to participants' readiness to undertake the practical tasks involved in investigating and challenging the MHRC. A high rate of volunteering for such tasks was most notable in groups of our participants who afterwards reported a sense of euphoria. When struggle generates great excitement: it may well facilitate the pooling of commitments and resources necessary to act collectively and efficaciously.

Relations with the Coordinator. For a group to mobilize, the authority must be deauthorized, thereby destroying the claims of the agentic role on the potential challengers. This is difficult to do in the MHRC encounter, because the coordinator is ever present and active. When he is not physically in the room, participants know he 
is watching them on the monitor in the adjoining room.

Personal attacks on the agents of authority can aid in mobilizing for a struggle but such attacks can also backfire. It is easier to challenge an authority system when its agents are personally obnoxious than when they are firm but civil. Challenges often produce social control errors by higher agents of authority that can be exploited by potential challengers to encourage resistance and struggle.

If authorities act with civility; however, personal attacks can easily backfire. In the MHRC encounter, for example, many participants show a tendency to humanize the encounter. The coordinator is distant, makes no play for sympathy, and does not ever raise his voice or attack group members. In contrast, he is sometimes attacked and made the target of ridicule for his apparent moral obtuseness. He sometimes gets flustered and there can be little doubt that the participants perceive when they are giving him a hard time.

Resistance and struggle are undercut when people begin feeling sorry for the coordinator in his unfortunate job. Such understandable and honorable reactions are, in this instance, demobilizing. They present challengers with the temptation to comply on humanitarian grounds. If the coordinator is just a poor soul trying to do an unpleasant and difficult job, why not go along with what he asks to spare him further humiliation?

Besides the danger of provoking a sympathetic reaction, personal attacks on the coordinator are too encounter-centered for an effective struggle against the MHRC. For successful struggle, deauthorization must reach a point at which the coordinator becomes an irrelevancy. Successful resistance, even by a single person, is an important step in reaching this point. If anyone suspects concealed sanctions, he 
is disabused of this notion. The coordinator reveals no effective means for insuring compliance. Resistance breaks the magic spe1l: henceforth, those who continue to operate in the agentic role do so with recognition of an alternative.

To attack the MHRC, group members must reach the point where they simply ignore the coordinator as they make their own plans. This MHRC flunky no longer concerns them. If he intrudes on their conversation, this is taken as a signal for the group to meet someplace where it can discuss its plans without danger of being overheard by an MHRC spy. The ultimate relationship with the coordinator is no relationship, when a group is mobilizing for an attack on the MHRC.

\section{Conclusion}

The study of encounters with unjust authority is important for understanding resource mobilization. Encounters provide occasions in which events can alter the consciousness of participants about the operation of an authority system. They provide occasions on which solidarities and collective commitments can change rapidly and the strength of commitments to struggle can be assessed. They provide occasions in which social control errors by authorities may occur or be provoked, leading to the delegitimation of the authority system.

The MHRC encounter offers special advantages for understanding the general case. By mimimizing the role of external sanctions, it allows us to view more clearly the operation of the social psychological forces that maintain compliance. By drawing on previously unorganized participants, it allows us to view the emergence of organization. We do not suggest that what happens in encounters emerges de novo. On the contrary, we argue that in encounters as well as in 
sustained mobilization, participants invoke long standing principles and adopt familiar techniques of dealing with injustice. The MHRC encounter makes these processes of mobilization especially visible. Beyond these theoretical advantages, there are practical ones. The number of participants is small enough. so that one can follow the interaction and even record it on video-tape. 'It takes place, as does any encounter, in an encapsulated time frame, but, in the MHRC encounter, the boundaries of this time frame are controlled. Most important of all, the underlying structural situation can be repeated, allowing . $\therefore$ each set of participants to write, spontaneously, their own script of the encounter. Variations can be systematically introduced into these repetitions. 9

In the 33 groups that we have watched, with numerous replays of critical scenes, we have witnessed many that have moved in an hour from a collection of unacquainted strangers to a group that is planning an attack on the MHRC. The process we have observed appears in many ways as a microcosm of mobilization. Potentiál challengers grapple at the level of the encounter with problems that are functional analogues of the problems that sustained movement organizations face in the larger process of resource mobilization.

To be explicit, potential challengers in the encounter face the problem of overcoming the hegemony of the task frame. This is an analogue of challenging dominant beliefs or ideologies that support the existing structure. During certain historical periods, some of these system-maintaining beliefs hold virtually unchallenged sway. Potential challengers must break through the hegemony that such belief. systems hold in their constituency if they hope eventually to gain 
a commitment to a rebellious counter-ideology. Those intellectuals who articulate counter-ideologies have their facsimile among MHRC participants who articulate the alternative frame.

Potential challengers in the encounter face a series of problems of internal relations in the process of creating a nascent organization, and social movement organizations face an analogous set. Movement organizations must be built on the same two essential characteristics of an alternative authority system: a mechanism for selecting courses of collective action, and a claim on constituents for supporting these action commitments.

To create a commitment to a movement organization, it helps to have a sense of group loyalty or solidarity in the underlying constituency. Common political struggle is an important mechanism for creating it. For a movement organization to sustain a long-term challenge, it must find some way of dealing with internal conflict. Frequently, movement organizations must take risks by choosing courses of action where support is uncertain and the action demands greater sacrifices than their constituency may be ready to make. Movement organizations grow by passing such tests or decline by flunking them.

To be effective, movement organizations must be able to manage the logistics and coordinating tasks of mobilization. Sometimes their constituency is bursting with angry energy, ready and eager to act but without coordination. Spontaneous strikes and other sudden, uncoordinated acts of rebellion may leave the movement organization vulnerable to counterattack and in a state of internal chaos. If this energy is successfully channeled by the movement organization into effective collective action, the mutually reinforcing cycle of 
of commitment and collective efficacy described above for nascent organizations may be set in motion for full-fledged movement organizations. Potential challengers in the encounter must deauthorize agents of the authority system and undermine their claims for loyalty from the participants. Movement organizations frequently contend with authority systems over claims for the loyalty of the same constituency. When these claims conflict, the movement organization must undermine the authority's claim for compliance if it is to gain support in rebellious collective action. Dissent and resistance are important steps in the process of deauthorization. Dehumanization of the target can be and often is used to make an attack on agents of an authority system psychologically easier to sustain.

In suggesting that mobilization processes observable in encounters have analogues in larger mobilization processes, we do not mean to suggest perfect isomorphism. Study of encounters will not shed much light on how social movement cadre build organization over time among dispersed constituents, or how they act on long term strategies for dealing with allies and enemies. Participants in encounters may plan torcal1"meetings, conduct investigations, activate outside authorities, sustain commitment despite pressing concerns in everyday life, and so forth; but social movement organizers must actually cope with the difficulties inherent in such tasks.

In sum, we make a double plea for studying encounters. Particular encounters turn out to be watershed events in the growth and decline of important social movement organizations. The dynamics of such events and their relationship to the larger process of mobilization need to be understood. But there is an important further reason for 
the systematic study of encounters. The parallels between the problems faced in an encounter and those faced in a sustained challenge are rich enough to suggest that many of the solutions may follow a similar process. If so, encounters are important because they allow us to study the process of mobilization in miniature. 
Table 1

\section{Affidavit Resistance and Mobilization for Attack}

Mobilization

for struggle

Yes

No

$\mathrm{N}=31^{\mathrm{a}}$

Fisher Exact Prob. = .004

Affidavit Resistance

Complete

$72 \%(10)$

$28 \%$

14
Incomplete

$18 \%:(3)$

$82 \% \underline{(14)}$

17

Affidavit resistance and late protest is not really meaningful for the two early resisting groups. They are excluded from this and subsequent tables. Both groups eventually mobilized for struggle. 
Table 2

Early and Late Protest and Affidavit Resistance

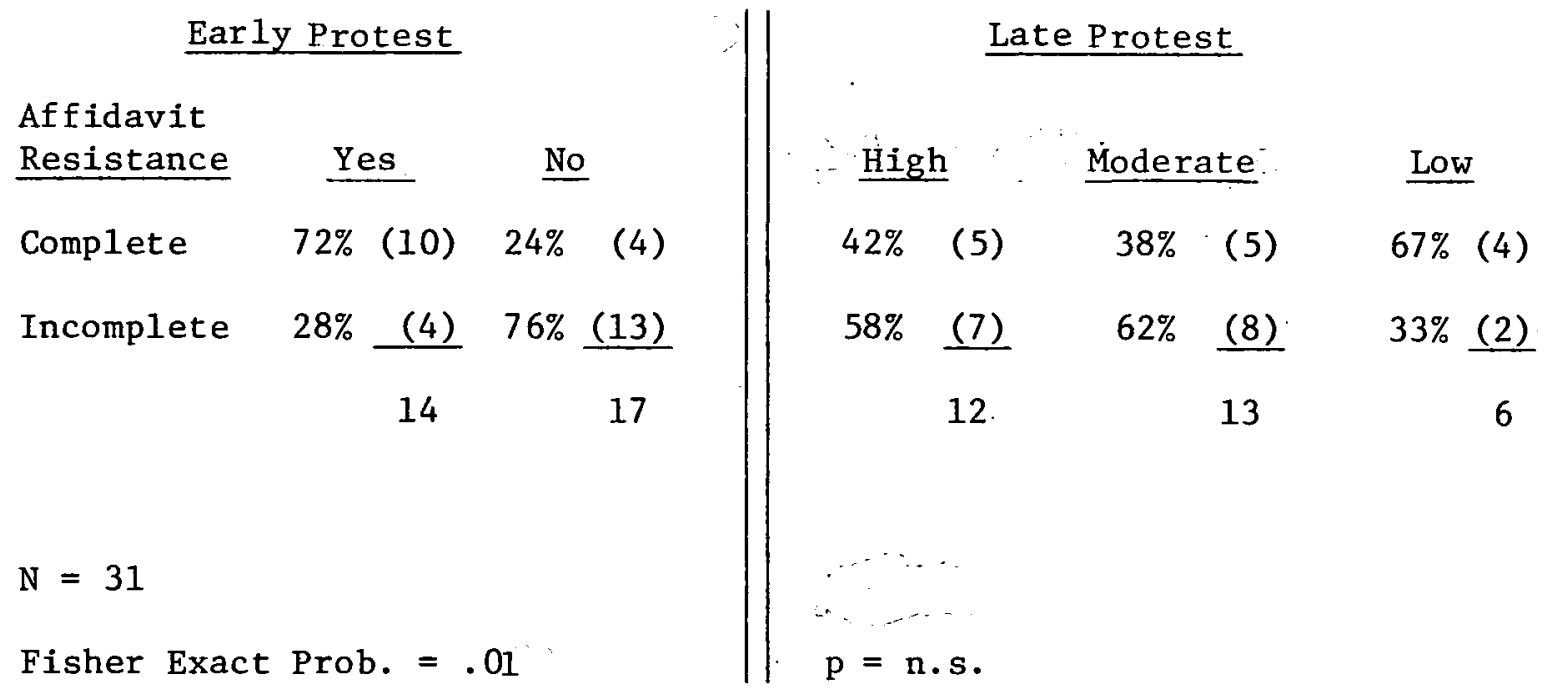


Table 3

Ear1y and Late Protest

$$
\begin{aligned}
& \text { Late } \\
& \underline{\text { Protest }} \\
& \text { High } \\
& \text { Moderate } \\
& \text { Low } \\
& \mathrm{N}=31 \\
& \mathrm{p}=\mathrm{n} . \mathrm{s} .
\end{aligned}
$$$$
\text { Early Protest }
$$$$
\text { Yes No }
$$$$
43 \%(6) \quad 35 \%(6)
$$$$
43 \%(6) \quad 41 \%(7)
$$$$
14 \% \text { (2) } \quad 24 \% \text { (4) }
$$$$
14
$$$$
17
$$ 


\section{Footnotes}

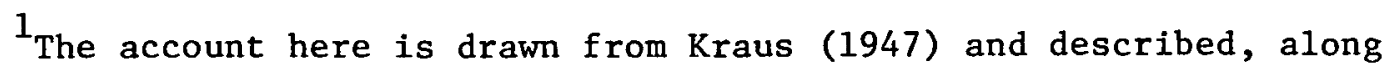
with other similar encounters, in Brecher (1972).

${ }^{2}$ For a complete description of the basic fabrication and an extensive series of variations, see Milgram (1974). The quoted material is from Milgram.

${ }^{3}$ It may not always be easy to know how participants view an authority system, since there are powerful reasons why people comply in spite of negative feelings. Clearly, one cannot infer their view of authority simply by observing their behavior but must rely on other, independent evidence.

${ }^{4}$ Since the Milgram encounter is not collective, this distinction among collective encounters is irrelevant to it. A recent article by Aveni (1977) on "The Not-So-Lonely Crowd" would suggest that, in the Berkeley incident, the crowd in Sproul Plaza may have contained more organization than would at first appear. At the very least, it is likely that many small friendship and acquaintance clusters linked crowd members to each other in significant ways.

5or example, 11 of the groups had a "mobilizing agent" in them -a confederate who attempted to fulfill certain mobilizing functions for the group. . -

${ }^{6}$ Signing in the case of one of the apparently compliant groups is misleading. This group successfully resisted early and decided 
collectively to sign the affidavit, having only given true opinions throughout. It's also worth noting that six of the 12 divided groups were ones in which only one or two people signed.

${ }^{7}$ This section draws heavily on the work of Erving Goffman, particularly Frame Analysis (1974).

${ }^{8}$ Before turning from the discussion of frame to other processes, it is worth noting a peculiarity of the MHRC encounter: the fact that this encounter is a fabrication may be and sometimes is suspected by the participants. Some suggest, with varying degrees of seriousness and conviction, that they expect to be told that they are on candid camera or in a psychological experiment.

Suspicion of this sort about the task frame is not often an issue in natural encounters. It is a complex problem that must be confronted in interpreting our data but will not concern us in this paper. In some early runs, the problem was quite serious, but suspicion was rarely voiced in later runs.

Belief in a fabrication has a complicated relationship to rebellious collective action. On the one hand, it can have a mobilizing effect by diminishing any possibility of negative sanctions for noncompliance. On the other hand, if the encounter is merely a fabrication, then there is no real injustice in allowing the unimpeded operation of the authority system and no reason not to go along. To complicate matters further, participants may not simply adopt or reject the possibility that the MHRC encounter is a fabrication, but may entertain it with various degrees of probability along with the belief 
that the encounter is real. Such a dual frame suggests some caution in action while one awaits further information. Although suspicion of a fabrication is not relevant to encounters in general, it must be confronted and disentangled in any interpretation of the frames being used by MHRC participants .

9. The major disadvantage is that fabrications raise quite serious and troubling ethical questions which we will address at length elsewhere. 
A. Aveni, "The Not-So-Lonely Crowd: Friendship Groups in Collective Behavior." Sociometry Vol. 40, No. 1 (March, 1977), pp. 96-99.

J. Brecher, "Strike!" Fawcett Publications, Inc,, Greewich, Connecticut, 1972 .

E. Goffman, "The Presentation of Self in Everyday Life." Doubleday Anchor Books, New York, 1959.

E. Goffman, "Frame Analysis." Harvard University Press, Cambridge, Massachusetts, 1974 .

M. Heirich, "The Spiral of Conflict: Berkeley, 1964." Columbia University Press, New York, 1971.

H. Kraus, "The Many and the Few." Plantin, Los Angeles, 1947.

S. Milgram, "Obedience to Authority." Harper and Row (Harper Colophon), New York, 1974.

S. Milgram, "Obedience" (A Filmed Experiment). New York University Film Library, 1965. 
Chart 1

Patterns of Response

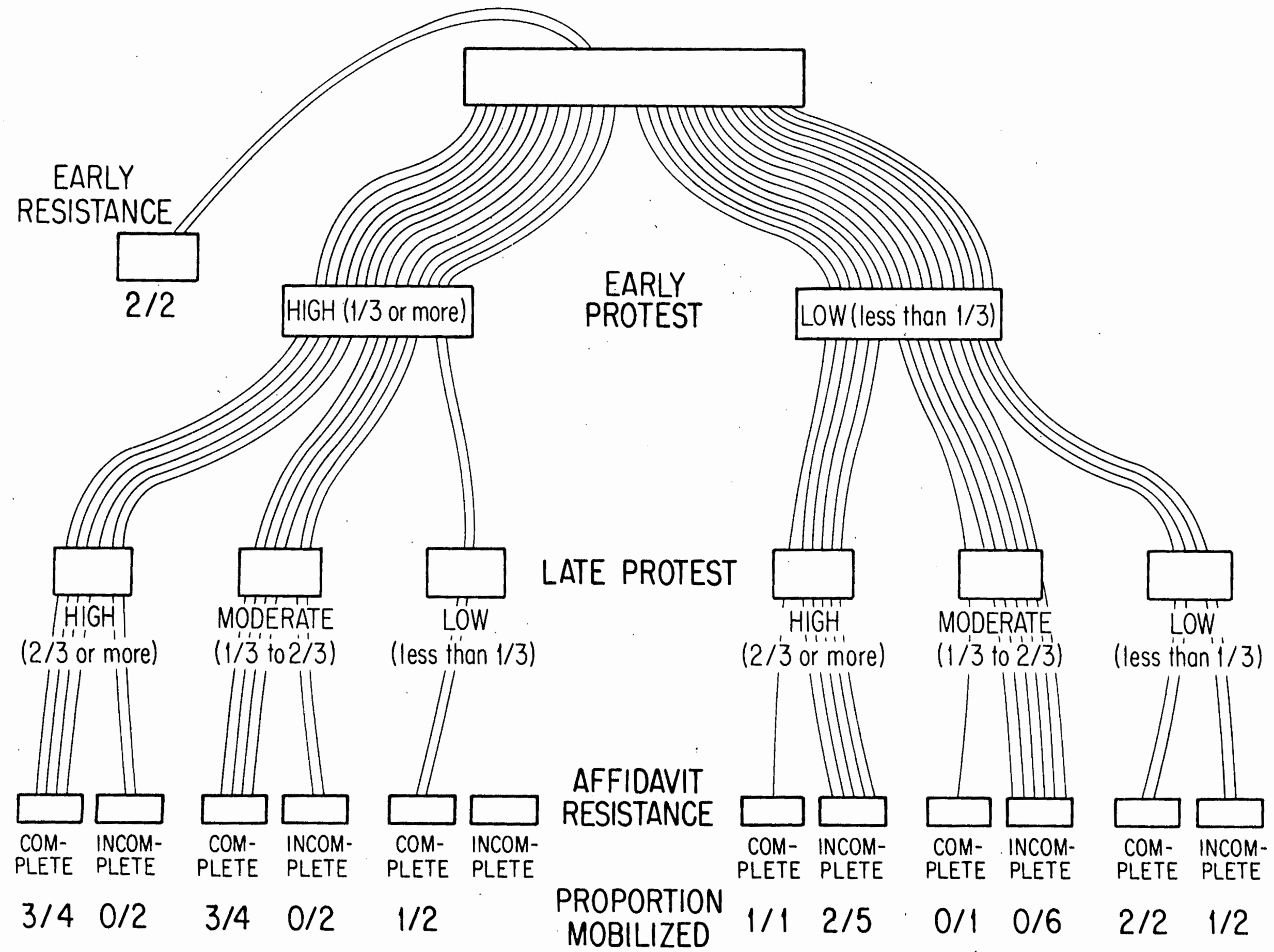

